\title{
ECLETICA
}

www.scielo.br/eq

Volume 31, número 4, 2006

\section{Isolation of lignans glycosides from Alibertia sessilis (Vell.) K. Schum. (Rubiaceae) by preparative high-performance liquid chromatography}

\author{
V. C. da Silva ${ }^{a}$, G. H. Silvab, V. da S. Bolzani, M. N. Lopes ${ }^{* a}$ \\ "Departamento de Química Orgânica, Instituto de Química, Universidade Estadual “Júlio de Mesquita Filho”, \\ CP 355, CEP 14800-900, Araraquara, São Paulo - Brazil. \\ ${ }^{b}$ Departamento de Química, Universidade Federal de Sergipe, CEP 49100-000, Aracajú, Sergipe - Brazil. \\ "Email address: mnlopes@iq.unesp.br
}

\begin{abstract}
Enantiomeric aglycone lignans contained in a mixture were separated from a fraction of the extract of the stems of Alibertia sessilis (Vell.) K. Schum. (Rubiaceae) by preparative high-performance liquid chromatography. An efficient and fast separation can be achieved with methanol-water $(30: 70, \mathrm{v} / \mathrm{v})$. Their structures were identified as (+)-lyoniresinol $3 \alpha-O$ - $\beta$-glucopyranoside and (-)lyoniresinol $3 \alpha-O-\beta$-glucopyranoside, being reported for the first time in Rubiaceae.
\end{abstract}

Keywords: Rubiaceae; Alibertia sessilis; enantiomeric aglycone lignans; HPLC.

\section{Introduction}

Rubiaceae is widely distributed in Brazilian main ecosystems (Amazon, Cerrado and Atlantic Forest). This family is well known due to economic and therapeutic importance of these species, specially Coffea arabica and Cinchona ledgeriana [12]. Reported chemical constituents of Rubiaceae revealed a great diversity of secondary metabolites such as iridoids, alkaloids, anthraquinones, flavonoids, phenolics derivatives, triterpenes and diterpenes [1].

Few chemical studies of Alibertia have been reported resulting in the isolation of several triterpenes [2-4], iridoids [5], flavonoids [6] and caffeic acid esters [2].

Alibertia sessilis (Vell.) K. Schum., popularly known as "marmelada-de-cachorro", is distributed in the states of Ceará, Mato Grosso, Goiás and Minas Gerais. The plant possesses fruits with succulent pulp, black when ripe, which are consumed by birds in general [7].

From the stems of $A$. sessilis we report the isolation of a mixture of lignan glycosides. The separation of (+)-lyoniresinol $3 \alpha-O-\beta$-glucopyranoside (1) and (-)-lyoniresinol $3 \alpha-O-\beta$ glucopyranoside ()ㅜ by conventional methods such as silica gel and RP18 low pressure column chromatography was unsuccessful. However, it was quite easy and fast to purify each compound by preparative high-performance liquid chromatography (HPLC). Reversed-phase HPLC is commonly used for the separation of compounds present in complex mixtures of plant extracts [8-9].

Nuclear magnetic resonance (NMR) analysis was used to identify the compounds. Compound $\underline{1}$ exhibit antioxidant [10] and antitumor-promoting activities [11]. These compounds, whose chemical structures are given in Figure 1, are being reported for the first time in Rubiaceae. 

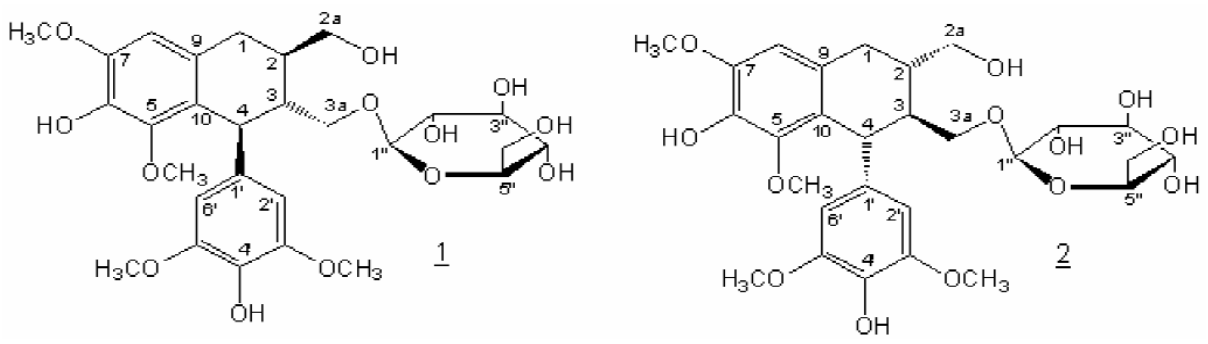

Figure 1. Lignans glucosides isolated from the stems of Alibertia sessilis.

\section{Experimental details}

\section{Plant material}

Alibertia sessilis (Vell.) K. Schum. (Rubiaceae) was collected in the Estação Ecológica Experimental de Mogi-Guaçu, São Paulo State, Brazil in November 2003. A voucher specimen was deposited at the Herbário do Instituto Botânico da Secretaria do Meio Ambiente de São Paulo (nº SP 370.914).

\section{Apparatus}

The high-performance liquid chromatography (HPLC) (Shimadzu, Japan) equipment used was a CLASS-VP Ver.5.41 system comprised a Shimadzu SPD10Avp UV detector, a Shimadzu LC-8ATvp Multisolvent Delivery System, a Shimadzu SCL-10Avp controller, a Shimadzu LC pump, a Degasser Shimadzu DGU-14A and a CLASS-VP Ver.5.41 workstation (Shimadzu, Japan). HPLC-grade methanol was purchased from J.T. Baker (Baker-Mallinckrodt, Phillipsburg, NJ, USA). HPLC-grade water (18 $\mathrm{M} \mathrm{cm}$ ) was obtained using a Millipore Milli-Q purification system (Millipore Co., Bedford, MA, USA).

\section{Extraction, fractionation and preparation of sample}

Dried and powered stems (50.0 g) of $A$. sessilis were successively extracted with ethanol at room temperature. The solvent was removed under reduced pressure yielding $3.7 \mathrm{~g}$ of crude extract. This extract was dissolved in methanolwater (80:20, v/v) and partitioned with hexane, ethyl acetate and $n$-butanol to yield $0.5 \mathrm{~g}$ of hexane extract, $1.4 \mathrm{~g}$ of ethyl acetate extract and $1.3 \mathrm{~g}$ of $n$-butanol extract after evaporated to dryness under reduced pressure.

The ethyl acetate extract was submitted to column chromatography using Sephadex LH-20.
The column was eluted with methanol, to give 15 fractions reunited after thin layer chromatography (TLC) analysis. Fractions 2-3 (146.4 mg) were subjected to chromatography on a RP18 column using a water-methanol gradient system affording iridoid geniposidic acid $(11.8 \mathrm{mg})$, a derivative fenolic glycoside $(6.7 \mathrm{mg})$ not yet identified and the mixture of lignans glycosides $(36.6 \mathrm{mg})$.

\section{Separation procedure}

The separation of lignans was performed using a Phenomenex Luna RP18 (2) column (250 x $21.20 \mathrm{~mm}$ I.D. x $10 \mu \mathrm{m}$, Torrance, CA, USA) in a Rheodyne 7125 sample injector with a $2.0 \mathrm{~mL}$ sample loop (Rheodyne, Cotati, CA, USA). The mobile phase composed of methanol-water (30:70, v/v, isocratic system) was eluted using a flow-rate of $10.0 \mathrm{~mL} \mathrm{~min}^{-1}$, the injection volume was $1.0 \mathrm{~mL}$. Pure lignans were examined by HPLC on an analytical column. The analysis was performed with a Phenomenex Luna RP18 (2) column $(250$ x $4.6 \mathrm{~mm}$ I.D. x $5 \mu \mathrm{m}$, Torrance, CA, USA) in a Rheodyne 7125 sample injector with a $20 \mu \mathrm{L}$ sample loop (Rheodyne, Cotati, CA, USA). The mobile phase composed of methanol-water $(30: 70, \mathrm{v} / \mathrm{v}$, isocratic system) was eluted at a flowrate of $1.0 \mathrm{~mL} \mathrm{~min}^{-1}$, the injection volume was 20 $\mu \mathrm{L}$. For both preparative and analytical HPLC, the detector was set as $238 \mathrm{~nm}$.

\section{Structural identification of the compounds}

The NMR spectra in $\mathrm{CD}_{3} \mathrm{OD}$ of all compounds were obtained using a Varian, INOVA 500 spectrometer (Varian, Palo Alto, CA, USA), operating at $500 \mathrm{MHz}$ for ${ }^{1} \mathrm{H}$ and $125 \mathrm{MHz}$ for ${ }^{13} \mathrm{C}$, two-dimensional technique such as $g \mathrm{COSY}$ (gradient chemical shift correlation spectroscopy), $g$ HMQC (gradient heteronuclear multiple quantum coherence) and $g \mathrm{HMBC}$ (gradient heteronuclear 
multiple bond connectivity) were used to fully elucidate the structure of compounds. Chemical shifts were given in $\delta(\mathrm{ppm})$ using tetramethylsilane (TMS) as internal standard.

(+)-lyoniresinol $3 \alpha-O$ - $\beta$-glucopyranoside (6.7 $\mathrm{mg}, \mathbf{1}$ ): ESI-MS (negative): $\mathrm{m} / \mathrm{z} 581.2303$ [M - H] ${ }^{-}$ . ${ }^{1} \mathrm{H}$ NMR $\left(\mathrm{CD}_{3} \mathrm{OD}, 500 \mathrm{MHz}\right): \delta 1.61(1 \mathrm{H}, m, \mathrm{H}-$ 2), $\delta 1.99(1 \mathrm{H}, m, \mathrm{H}-3), \delta 2.51(1 \mathrm{H}, d d, J=12$ and $15 \mathrm{~Hz}, \mathrm{H}-1)$ and $2.61(1 \mathrm{H}, d d, J=5$ and $15 \mathrm{~Hz}, \mathrm{H}-$ $1), \delta 3.11-3.15$ (2H, $m, \mathrm{H}-2$ " and H-3"), $\delta 3.18$ (1H, $m, \mathrm{H}-4 "), \delta 3.24-3.27$ (1H, $m, \mathrm{H}-5$ "), $\delta 3.25$ $\left(3 \mathrm{H}, \mathrm{s}, \mathrm{CH}_{3} \mathrm{O}-5\right), \delta 3.35(1 \mathrm{H}, d d, J=4$ and $10 \mathrm{~Hz}$, $\mathrm{H}-3 \mathrm{a}), \delta 3.43(1 \mathrm{H}, d d, J=6.5$ and $11 \mathrm{~Hz}, \mathrm{H}-2 \mathrm{a})$, 3.55 (2H, m, H-2a and H-6"), $\delta 3.64(6 \mathrm{H}, \mathrm{s}$, $\mathrm{CH}_{3} \mathrm{O}-3^{\prime}$ and $\mathrm{CH}_{3} \mathrm{O}-5$ '), $\delta 3.73$ (1H, $m, \mathrm{H}-6$ '), $\delta$ $3.76\left(3 \mathrm{H}, \mathrm{s}, \mathrm{CH}_{3} \mathrm{O}-7\right), \delta 3.78(1 \mathrm{H}, d d, J=5.5$ and $10 \mathrm{~Hz}, \mathrm{H}-3 \mathrm{a}), \delta 4.18$ (1H, $d, J=7.5 \mathrm{~Hz}, \mathrm{H}-1$ '), $\delta$ $4.32(1 \mathrm{H}, d, \mathrm{~J}=5.5 \mathrm{~Hz}, \mathrm{H}-4), \delta 6.32(2 \mathrm{H}, s, \mathrm{H}-2$ ' and $\mathrm{H}-6$ '), $\delta 6.48(1 \mathrm{H}, s, \mathrm{H}-8) .{ }^{13} \mathrm{C} \mathrm{NMR}\left(\mathrm{CD}_{3} \mathrm{OD}\right.$, $125 \mathrm{MHz}): \delta 33.8$ (C-1), $\delta 40.6(\mathrm{C}-2), \delta 42.7$ (C$4), \delta 46.7(\mathrm{C}-3), \delta 56.6\left(\mathrm{CH}_{3} \mathrm{O}-7\right), \delta 56.9\left(\mathrm{CH}_{3} \mathrm{O}-\right.$ 3 ' and $\mathrm{CH}_{3} \mathrm{O}-5$ '), $\delta 60.2\left(\mathrm{CH}_{3} \mathrm{O}-5\right), \delta 62.8(\mathrm{C}-6$ "'), $\delta 66.2$ (C-2a), $\delta 71.5$ (C-3a), $\delta 71.7$ (C-4”), $\delta 75.2$ (C-2"), $\delta 77.9$ (C-3"), $\delta 78.2$ (C-5"), $\delta 104.8$ (C1 "), $\delta 107.0$ (C-2' and C-6'), $\delta 107.9(\mathrm{C}-8), \delta$ 126.4 (C-10), $\delta 130.2$ (C-9), $\delta 135.0$ (C-4'), $\delta$ 138.9 (C-6), $\delta 139.3$ (C-1'), $\delta 147.6$ (C-5), $\delta 148.6$ (C-7), $\delta 149.0$ (C-3' and C-5').

(-)-lyoniresinol $3 \alpha$-O- $\beta$-glucopyranoside $(5.8$ $\mathrm{mg}, \underline{2}$ ): ESI-MS (negative): $\mathrm{m} / \mathrm{z} 581.2303$ [M $\mathrm{H}]-.{ }^{1} \mathrm{H}$ NMR $\left(\mathrm{CD}_{3} \mathrm{OD}, 500 \mathrm{MHz}\right): \delta 1.58(1 \mathrm{H}, m$, $\mathrm{H}-2), \delta 2.03(1 \mathrm{H}, m, \mathrm{H}-3), \delta 2.56$ (2H, $m, \mathrm{H}-1), \delta$ 3.03-3.11 (4H, $m, \mathrm{H}-2$ ", H-3", H-4" and H-5"), $\delta$ $3.23\left(3 \mathrm{H}, \mathrm{s}, \mathrm{CH}_{3} \mathrm{O}-5\right), \delta 3.50(2 \mathrm{H}, m, \mathrm{H}-2 \mathrm{a}), \delta$ 3.51 (1H, $m, \mathrm{H}-3 \mathrm{a}), \delta 3.58$ (1H, $m, \mathrm{H}-6$ "), $\delta 3.65$ $\left(6 \mathrm{H}, \mathrm{s}, \mathrm{CH}_{3} \mathrm{O}-3^{\prime}\right.$ and $\mathrm{CH}_{3} \mathrm{O}-5$ ' $), \delta 3.72(1 \mathrm{H}, m, \mathrm{H}-$ $3 \mathrm{a}), \delta 3.74\left(1 \mathrm{H}, m, \mathrm{H}-6\right.$ ") $\delta 3.75\left(3 \mathrm{H}, \mathrm{s}, \mathrm{CH}_{3} \mathrm{O}-\right.$ 7), $\delta 4.03$ (1H, $d, J=7.5 \mathrm{~Hz}, \mathrm{H}-1$ ”), $\delta 4.13(1 \mathrm{H}, d$, $J=6.5 \mathrm{~Hz}, \mathrm{H}-4), \delta 6.31$ (2H, s, H-2' and H-6'), $\delta$ $6.48(1 \mathrm{H}, s, \mathrm{H}-8) .{ }^{13} \mathrm{C} \mathrm{NMR}\left(\mathrm{CD}_{3} \mathrm{OD}, 125 \mathrm{MHz}\right)$ : $\delta 33.8(\mathrm{C}-1), \delta 41.6(\mathrm{C}-2), \delta 43.2(\mathrm{C}-4), \delta 46.6(\mathrm{C}-$ $3), \delta 56.6\left(\mathrm{CH}_{3} \mathrm{O}-7\right), \delta 56.9\left(\mathrm{CH}_{3} \mathrm{O}-3\right.$ ' and $\mathrm{CH}_{3} \mathrm{O}-$ 5'), $\delta 60.1\left(\mathrm{CH}_{3} \mathrm{O}-5\right), \delta 62.7(\mathrm{C}-6$ ") $), \delta 66.2(\mathrm{C}-$ 2a), $\delta 71.6$ (C-4"), $\delta 72.0$ (C-3a), $\delta 75.1$ (C-2"), $\delta$ 77.9 (C-3"), $\delta 78.2$ (C-5"), $\delta 104.2$ (C-1"), $\delta$ 107.1 (C-2' and C-6'), $\delta 107.8$ (C-8), $\delta 126.2$ (C10), $\delta 130.2$ (C-9), $\delta 135.0$ (C-4'), $\delta 138.9$ (C-6), $\delta 139.4\left(\mathrm{C}-1^{\prime}\right), \delta 147.5(\mathrm{C}-5), \delta 148.7(\mathrm{C}-7), \delta$ 149.0 (C-3' and C-5').

\section{Results and Discussion}

The crude extract from stems of $A$. sessilis was partitioned using hexane, ethyl acetate and $n$-butanol. The ethyl acetate extract afforded geniposidic acid, a derivative fenolic glycoside and a third compound. The ${ }^{1} \mathrm{H}$ - and ${ }^{13} \mathrm{C}-\mathrm{NMR}$ data for this last showed overlapping signals, suggesting that third compound could be a diastereomeric mixture of lignans containing enantiomeric aglycone parts that were not separated. Conventional methods such as silica gel and RP18 low pressure column chromatography were not successful to separate this lignans.

So, this partially purified sample was analysed by HPLC and a series of experiments was performed to determine the optimal solvent system for the HPLC separation. The following systems were tested: methanol-water (35:65, 30:70, 25:75, v/v), and the separation time were: $18 \mathrm{~min}, 25 \mathrm{~min}$ and 42 min, respectively, for an analytical separation run. But, despite of first system has faster separation time, the peaks concerning to lignans didn't have good separation, and the third system had a long separation time. A good and fast separation can be achieved with the system methanol-water (30:70, v/v).

Another evidence that the mixture was composed of a enantiomeric aglycone parts is the identical UV spectras with absorption maximum at 215 and $270 \mathrm{~nm}$ and one spot when analysed by TLC.

The result obtained from the partially purified sample of Alibertia sessilis by preparative HPLC is showed in Fig. 2.

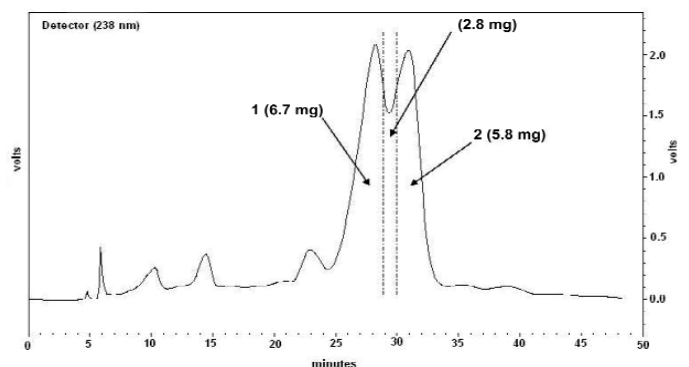

Figure 2. Preparative HPLC chromatogram of the partially purified sample of Alibertia sessilis. Column: Phenomenex Luna RP18 (2) column (250 x 21.20 mm I.D. x $10 \mu \mathrm{m}$ ); mobile phase: methanol-water (30:70, $\mathrm{v} / \mathrm{v})$; flow-rate: $10.0 \mathrm{~mL} \mathrm{~min}^{-1}$; monitoring at $238 \mathrm{~nm}$. Peak 1: (+)-lyoniresinol $3 \alpha-O-\beta$ - glucopyranoside. Peak 2: (-)-lyoniresinol $3 \alpha-O-\beta$ - glucopyranoside. 


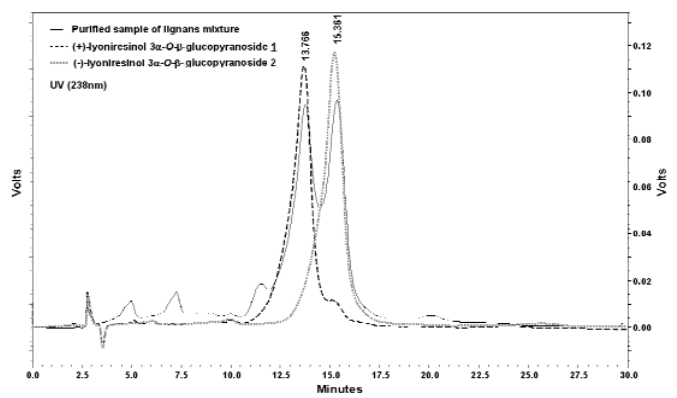

Figure 3. Analytical HPLC chromatogram of the partially purified sample of Alibertia sessilis and the compounds isolated. Column: Phenomenex Luna RP18 (2) column ( 250 x $4.6 \mathrm{~mm}$ I.D. x $5 \mu \mathrm{m})$; mobile phase: me-

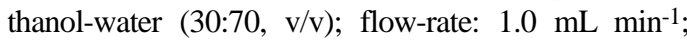
monitoring at $238 \mathrm{~nm}$. Peak at $t_{R}=13.766 \mathrm{~min}$ : (+)-lyoniresinol $3 \alpha-O-\beta$-glucopyranoside $\underline{\mathbf{1}}$. Peak at $t_{R}=$ 15.361 min: (-)-lyoniresinol 3 $\alpha-O-\beta$-glucopyranoside $\underline{\mathbf{2}}$.

After this separation, each fraction was collected, weighed and analysed by ${ }^{1} \mathrm{H}$ - and ${ }^{13} \mathrm{C}-\mathrm{NMR}$ and HPLC (fig. 3). The relative configurations at $\mathrm{C}$ 2, C-3 and C-4 were estabilished by comparison with literature data [12]. The coupling constants $(J$ $=7.5 \mathrm{~Hz})$ of the anomeric proton signal of the glucosyl moiety demonstrated that sugar has b- anomeric configuration [13]. The peak 1 fraction was identified as (+)-lyoniresinol $3 \alpha-O$ - $\beta$-glucopyranoside (1) and the peak 2 fraction as (-)lyoniresinol $3 \alpha-O$ - $\beta$-glucopyranoside (2).

\section{Conclusions}

Reversed-phase HPLC was successful in the preparative separation of a mixture containing enantiomeric aglycone parts, it was easy and fast to purify each compound of the mixture. So, this study contributed significantly to improve the knowledge about secondary metabolites of more one species of Brazilian Cerrado, when these compounds are being reported for the first time in Rubiaceae.

\section{Acknowledgements}

The authors are grateful to Fundação de Amparo à Pesquisa do Estado de São Paulo (FAPESP) for financial support and to Conselho Nacional de Desenvolvimento Científico e Tecnológico (CNPq) for a fellowship granted for to V.C.S.

Recebido em: 16 /10/ 2006.

Aceito em: 08 /12/ 2006.

V. C. da Silva, G. H. Silva, V. da S. Bolzani, M. N. Lopes. Isolamento de lignanas glicosiladas de Alibertia sessilis (Vell.) K. Schum. (Rubiaceae) por cromatografia líquida de alta eficiência preparativa.

Resumo: Agliconas enantioméricas de lignanas, contidas numa mistura, foram separadas de uma fração do extrato dos galhos de Alibertia sessilis (Vell.) K. Schum. (Rubiaceae) por cromatografia líquida de alta eficiência preparativa. Uma separação eficiente e rápida pode ser conseguida com a fase móvel metanol-

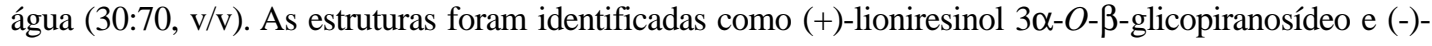
lioniresinol $3 \alpha-O$ - $\beta$-glicopiranosídeo, sendo descritas pela primeira vez em Rubiaceae.

Palavras-chave: Rubiaceae; Alibertia sessilis; agliconas enantioméricas de lignanas; HPLC.

\section{References}

[1] V. da S. Bolzani, M. C. M. Young, M. Furlan, A. J. Cavalheiro, A. R. Araújo, D. H. S. Silva, M. N. Lopes, Recent Res. Devel. Phytochem. 5 (2001) 19.

[2] V. da S. Bolzani, L.M.V. Trevisan, M.C.M. Young, Phytochemistry 30 (6) (1991) 2089.

[3] C. B. Brochini, D. Martins, N. F. Roque, V. da S. Bolzani, Phytochemistry 36 (5) (1994) 1293.

[4] R. S. G. Olea, N. F. Roque, V. da S. Bolzani, J. Braz. Chem. Soc. 8 (3) (1997) 257.

[5] M. C. M. Young, M. R. Braga, S. M. C. Dietrich, H.E. Gottlieb, L. M. V. Trevisan, V.da S. Bolzani, Phytochemistry 31 (10) (1992) 3433.

[6] J. H. S. Luciano, M. A. S. Lima, E. B. Souza, E. R.
Silveira, Biochem. Syst. Ecol. 32 (2004) 1227.

[7] M. Pio-Correa, Dicionário de plantas úteis do Brasil e das plantas exóticas cultivadas, Ministério da Agricultura, Brazil, 1974.

[8] K. Robards, J. Chromatogr. A. 1000 (2003) 657.

[9] H. M. Merken, G. R. Beecher, J. Agric. Food Chem. 48 (200) 577.

[10] P. Thongphasuk, R. Suttisri, R. Bavovada, R. Verpoorte, Fitoterapia 75 (2004) 623.

[11] H. Gao, L. Wu, M. Kuroyanagi, K. Harada, N. Kawahara, T. Nakane, K. Umehara, A. Hirasawa, Y. Nakamura, Chem. Pharm. Bull. 51 (11) (2003) 1318.

[12] H. Achenbach, M. Löwel, R. Waibel, M. Gupta, P. Solis, Planta Med. 58 (1992) 270.

[13] I. Kitagawa, M. Sakagami, F. Hashiuchi, L. J. Zhou, M. Yoshikawa, J. Ren, Chem. Pharm. Bull. 37 (4) (1989) 551. 